\title{
Integrating 'Principles of Effective Intervention' into Domestic Violence Intervention Programs: New Opportunities for Change and Collaboration
}

\author{
Dana L. Radatz ${ }^{1} \cdot$ Tara N. Richards ${ }^{2}$. Christopher M. Murphy ${ }^{3}$ - Lisa J. Nitsch ${ }^{4}$. \\ Angelique Green-Manning ${ }^{4}$. Ann Marie Brokmeier ${ }^{4}$. Charvonne N. Holliday \\ Received: 14 August 2020 / Accepted: 8 February 2021 / \\ Published online: 12 July 2021 \\ (c) Southern Criminal Justice Association 2021
}

\begin{abstract}
Several evaluations and meta-analytic reviews have suggested that domestic violence (DV) treatment programs have only a modest impact on reducing DV recidivism. In response, a growing number of scholars and practitioners have called for the integration of evidence-based practices into DV treatment programming. In recent years, one leading approach has been to explore the infusion of the 'principles of effective intervention (PEI), the prevailing evidence- based practice in correctional programming, into DV treatment. Findings from initial empirical studies from scholars and practitioners working to infuse the PEI into DV treatment programs have shown promise. This article provides an overview of the PEI and research exploring the integration of the PEI into DV treatment; a discussion on how these research findings can inform DV treatment programs interested in adopting a PEI framework; and practitioners' perspectives on implementing programmatic changes and collaborating on evaluation research while also continuing to provide DV treatment.
\end{abstract}

Keywords Domestic violence - Batterer intervention treatment - Principles of effective intervention $\cdot$ Risk assessments

\section{Introduction}

The concept of domestic violence (DV) treatment, also known as batterer intervention programs or BIPs, first emerged in the late 1970s, following the raised awareness of DV as a social problem during the second wave of the women's rights movement. The first DV treatment programs were formed from grassroots efforts, as a group of male, profeminist advocates formed EMERGE in Boston in 1977, and soon after, other DV treatment programs began to form across the United States (EMERGE,

Dana L. Radatz

dradatz@niagara.edu

Extended author information available on the last page of the article 
2000; Saunders, 2008). In the years that followed, the United States' courts began to sentence offenders to the community-based DV treatment programs, and the growth and use of DV treatment programs continued (Hilton \& Harris, 2009). By 2008, 45 of the 50 states had developed guidelines or standards for DV treatment programs, which included program characteristic requirements such as program duration and philosophy (Maiuro \& Eberle, 2008). As they proliferated, DV treatment programs were often hybridized, meaning programs were developed with various curriculums and philosophical approaches mixed together, often making each program unique to itself (Babcock et al., 2007; Gondolf, 2002). Soon to follow, results from a series of DV treatment program evaluations throughout the 1990s and early 2000s revealed variable results in reducing DV recidivism, with small overall effects that were significant in some, but not all, analyses (Eckhardt et al., 2013).

In recent years, scholars and practitioners have called for the infusion of evidence-based practices into DV treatment as a way to increase its effectiveness at reducing recidivism (Babcock et al., 2016; Cannon et al., 2016). Examining empirically supported principles of effective intervention (PEI; Bonta \& Andrews, 2017) found in correctional programming (Radatz \& Wright, 2016; Stewart et al., 2013) has been a leading suggestion for the integration of evidence-based practices into DV offender treatment. Initial research studies regarding the exploration of the PEI and DV offenders and their treatment have revealed promising findings (e.g., Hilton \& Radatz, 2018; Stewart et al., 2014). Similarly, scholars and practitioners transitioning programs to a PEI framework have reported favorable preliminary results (e.g., Hilton \& Radatz, 2018; Richards \& Murphy, 2018; Stewart et al., 2014). These preliminary findings prompt cautious optimism regarding the feasibility of infusing PEI into DV offender treatment and the potential payoff for treatment providers - positive client outcomes, collaborative partnerships, and new funding streams. Researcher-practitioner partnerships are essential to integrating these best practices into DV offender treatment programs and moving the field forward together. Therefore, this article has several primary purposes: First, we will provide an overview of the PEI and the relevant research on the exploration of the PEI among DV offenders and DV treatment. Second, we will discuss how the research findings can inform DV treatment programs transitioning to a PEI framework, and highlight the current successes and opportunities for continued improvement through state-based and site-specific examples. Finally, we will present practitioners' perspective regarding collaborating on research and making substantive programmatic changes to enhance evidence-based practice while continuing to provide DV offender treatment to clients.

\section{Theoretical Framework \& Research Explorations The Principles of Effective Intervention}

In pursuit of determining what worked in offender rehabilitation, a few researchers (namely Donald Andrews, James Bonta, and Paul Gendreau) utilized metaanalytic statistical strategies, narrative reviews, and personal clinical experience to determine which components of correctional programming (both institutional- and 
community-based) were effective in reducing general offender recidivism (Andrews et al., 1990a, b; Gendreau \& Andrews, 1996). The identified components resulted in the formation of the principles of effective intervention (PEI; Bonta \& Andrews, 2017). Systematic and quantitative research reviews revealed that programs following these principles produced greater reductions in recidivism (Bonta \& Andrews, 2017; Dowden \& Andrews, 2000; Gendreau, 1996; Smith et al., 2009). Among the PEI, the first three principles - risk, need, and responsivity (RNR) - are the most widely used and recognizable. The risk principle denotes that offenders should be assessed regarding their risk for reoffending, and subsequently classified into low-, medium-, and high-risk categories; then, offenders should be placed into a matching treatment intensity program (e.g., a medium-risk offender is matched with a medium intensity treatment program; Bonta \& Andrews, 2017). The need principle encompasses offender needs, which are divided into two types - criminogenic and non-criminogenic. Criminogenic needs are dynamic, modifiable risk factors closely associated with recidivism (e.g., substance abuse, antisocial personality patterns), whereas non-criminogenic needs are static risk factors more loosely associated with recidivism (e.g., low self-esteem, poor health). Therefore, the need principle states that a treatment program should place emphasis on uniformly assessing and addressing an offender's criminogenic needs (Bonta \& Andrews, 2017). The responsivity principle asserts that the style and modes of a treatment program's services should be cognitive- behavioral in nature, and accommodate an offender's ability, learning style, and strengths (Bonta \& Andrews, 2017). Two other commonly known principles, treatment and fidelity, have received significant attention in the research and practical realms (e.g., Farringer et al., 2019; Van Voorhis \& Salisbury, 2014). The treatment principle emphasizes two main components; first, treatment program staff should be firm-but-fair, respectful, and well-trained, and second, treatment services should utilize cognitive social learning strategies (Bonta \& Andrews, 2017). The fidelity principle directs that program staff should be qualified, well- trained, and supervised, and that all aspects of treatment services should be subject to evaluation and assessment for effectiveness (Andrews, 2006). Since its inception, the empirically derived PEI have garnered significant support in their identification as prevailing evidence-based practices in correctional programming (MacKenzie, 2006; Smith et al., 2009).

\section{The Empirical Exploration of the Principles of Effective Intervention with Domestic Violence Offenders}

Recent research studies have begun examining the risk and need principles among DV offenders. In 2014, Stewart and Power examined the risk profiles and criminogenic needs of DV offenders and non-DV offenders, and found that DV offenders had a higher average number of criminogenic needs when compared to non-DV offenders (Stewart \& Power, 2014). Further, the DV offenders had higher rates of selfreported mental health problems and learning disabilities, as well as more pervasive criminal histories (e.g., DV and non-DV offenses, property and sex offenses), when compared to non-DV offenders. In addition, Hilton and Radatz (2018) examined and 
compared criminogenic and noncriminogenic needs across three groups of offenders: DV offenders, non-DV violent offenders, and non-violent offenders. Their findings demonstrated that DV offenders exhibited problems across all eight of the criminogenic and noncriminogenic needs assessed. When compared to the two other groups of offenders, the DV offenders had a significantly higher number of criminogenic needs, and displayed the highest levels across all criminogenic domains except employment or school problems (Hilton \& Radatz, 2018). In a subsequent study that examined the criminogenic needs of DV offenders and their relation to IPV recidivism, Hilton and Radatz (2021) determined that all five of the criminogenic needs (i.e., antisocial personality traits, procriminal attitudes, substance use, poor relationships, and work/school problems) in their study were present among the offenders, and all but one (i.e., poor relationships) were significantly associated with IPV recidivism.

Two of the first studies to explore DV offenders, specifically, under a PEI framework, examined pre- and post-test scores on self-assessment questionnaires and facilitator-rated evaluations for incarcerated DV offenders assigned to a mediumintensity treatment program consisting (approximately 90 contact hours; Connors et al., 2012) or a high-intensity treatment program (over 300 contact hours; Connors et al., 2013). Both studies found significant pre- and post-treatment changes in client attitudes, motivation to change, and program-related skills and knowledge. In line with the risk principle, some scholars have worked to utilize existing DV risk assessment tools to help inform treatment intensity decisions for DV treatment programs under a PEI framework. For instance, in both studies noted previously, Connors and her team $(2012,2013)$ used the Spousal Assault Risk Assessment (SARA; Kropp \& Hart, 1997; Kropp et al., 1998, 1999) to assign offenders to medium- versus high-intensity programs. In 2019, Radatz and Hilton published an illustration on how to use the well-established tool, the Ontario Domestic Assault Risk Assessment (ODARA; Hilton et al., 2004, 2010) to assist DV treatment programs in their decisions regarding treatment intensity categories aligned with the PEI framework. Notably, the study findings from Hilton and Radatz's (2021) examination of criminogenic needs also indicated that the total number of criminogenic needs a DV offender had was significantly associated with the ODARA treatment intensity categories.

In another examination of DV treatment programs that align with the RNR principles of the PEI, Stewart and her colleagues (Stewart et al., 2014) conducted an outcome evaluation on the moderate- and high-intensity DV programs investigated by Connors and colleagues and delivered in Canadian prisons. As noted above, incarcerated offenders with a history of DV were assigned to moderate- or high-intensity DV programs based on a structured risk assessment (i.e., the SARA). Their study findings indicated that DV offenders who attended the high intensity program were less likely to reoffend, for both DV offenses and other forms of violence, compared to high-risk offenders who were either not assigned to treatment or dropped out. Although not statistically significant, their findings for offenders who attended the moderate intensity program showed a similar trend in reduced recidivism compared to moderate-risk offenders who did not receive or complete the intervention as well (Stewart et al., 2014). 
Another novel application used the PEI model as an organizing framework for a Second Responder program, which targeted the criminogenic risks and needs of IPV offenders with moderate to high-risk profiles (Scott et al., 2015). The family and victim services unit of the London, Ontario Police Department used mail and phone outreach to invite these individuals to participate in this intervention program while they were awaiting trial. The intervention was delivered in a oneon-one format by therapists at a community-based program for men who engage in IPV. Therapists administered the B-SAFER (Kropp \& Hart, 2004) to assess ongoing (dynamic) risk for IPV, provided participants with personalized feedback from their risk assessment, and invited them to attend additional voluntary sessions to address these risk factors. Treatment focused on helping participants connect with community resources for housing, food assistance, legal advice, substance abuse treatment, and mental health services. Therapists also used cognitive-behavioral strategies to address participants' abuse-supporting cognitions. On average, participants in the Second Responder program attended about 6 treatment sessions.

The 40 men who participated in the Second Responder program were compared to 40 randomly selected controls with similar risk profiles who were not successfully contacted through police outreach. The rate of criminal re-offending for domestic-violence was over twice as high in the comparison group (66\%) than the treatment group (30\%) during the first year of follow-up, and over three times higher in year $2(41 \%$ versus $12 \%)$. Significant differences were also observed for overall criminal re-offending and estimates of policing resources devoted to treated and untreated cases.

One noteworthy limitation of this study is the lack of random assignment to treatment and control groups. Although the two groups had similar IPV risk profiles, those in the treatment group may have had higher motivation to obtain help and avoid continued legal problems. In addition, the attained reach of the Second Responder program was limited: law enforcement was only able to successfully contact and recruit about $17 \%$ of eligible participants. The primary recruitment challenge was obtaining a working phone number, so it's possible that more individuals could be engaged in supportive interventions with better case tracking and recruitment strategies. It's also possible that having the initial contact come from someone outside the police department may increase willingness to engage. Despite these limitations, the obtained results were notable, indicating promise for further efforts to provide pre-trial supportive and risk-responsive services to moderate and highrisk IPV offenders.

Taken together, these initial studies exploring DV offenders and DV treatment in alignment with the PEI framework are promising. These preliminary studies show that DV offenders have high levels of criminogenic risk factors and needs and that DV risk assessment tools offer some guidance on assessing and placing DV offenders into distinct risk categories. Available findings indicate significant change in DVrelated attitudes and skills, with some evidence of lower recidivism for DV offenders who completed a treatment program under a PEI framework. In short, these empirical findings suggest that the PEI framework may be an appropriate avenue for infusing evidence-based practices into DV offender treatment. 


\section{Bridging the Research \& Practical Realms for PEI in DV Offender Treatment}

While a growing body of research lends support for the use of the PEI framework in DV offender treatment, there is still much to learn regarding the opportunities and challenges of adopting, evaluating, refining, and sustaining evidenced-based intervention strategies. It is well known that the first casualty of any meaningful programmatic change is the plan - what looks good on paper, or seems reasonable to a research team, may not always be easily implemented or work effectively in practice. As such, it is important to carefully consider existing examples of DV offender treatment programs that have adopted the PEI framework in order to identify current areas of strength, areas which require targeted improvement, and areas which represent gaps in our current knowledge and practice. In service to these considerations, we first describe two existing examples, one at the state level and one which is site-specific, and then provide first-hand accounts from DV treatment program staff regarding the planning and implementation of programmatic changes consistent with the PEI, while at the same time continuing to provide DV treatment to program clients.

\section{The Colorado Model}

Colorado is often lauded as one of the most progressive states in the country regarding its state standards for DV offender treatment. These standards are under the purview of the Domestic Violence Offender Management Board (DVOMB), which was created by the Colorado Legislature in 2000 and is supervised by the Department of Public Safety's Division of Criminal Justice. The legislative charge of the DVOMB is the "promulgation of Standards for the evaluation, treatment, and monitoring of convicted DV offenders and the establishment of an application and review process to approve Domestic Violence Treatment Providers" (16-11.8- 103, C.R.S). The DVOMB is also statutorily mandated to routinely evaluate Colorado's standards and develop revisions based on the evolving empirical evidence.

Colorado's standards were revised in 2010 with the specific intent of aligning them with the risk, need, and responsivity (RNR) principles (see Hansen et al., 2016; Radatz et al., 2020). Under the revised standards and consistent with the risk principle, treatment providers use an evidenced-based risk assessment, the Domestic Violence Risk and Needs Assessment, to assess clients' criminogenic risks and needs (Gover \& Richards, 2018). The DVRNA is a 14-item risk assessment tool derived from four well-known risk assessment tools, including the SARA, the ODARA, the Danger Assessment (Campbell et al., 2009), and the Domestic Violence Screening Instrument (DVSI; Williams \& Houghton, 2004), as well as the Level of Service Inventory (LSI, LSI-R; Andrews \& Bonta, 1995, 2001), the primary PEI framework risk assessment tool used in 
correctional programming. Consistent with the needs principle, treatment providers place offenders into one of three treatment intensity levels ( $A=$ low intensity, $\mathrm{B}=$ moderate intensity, or $\mathrm{C}=$ high intensity) based on a total risk score. Offenders who endorse any "critical risk factor" (i.e., any prior offenses against an intimate partner, drug/alcohol abuse, mental health issues, use and/or threatened use of weapons in current or past offenses, or access to firearms, suicidal/homicidal ideation, prior non-domestic violence offenses) are automatically placed in Level B or C.

Colorado's standards identify 18 "core competencies" that should be the focus of clients during their time in DV treatment (Gover \& Richards, 2018). Primary competencies include a commitment by the offender to eliminate abusive behaviors, a commitment to eliminate all other forms of violent behaviors, and acceptance of complete responsibility for their full history of committing abuse. Individualized treatment plans developed at intake may include additional competencies as indicated by their individual risk factors and treatment needs; treatment plans may also be revised during periodic treatment plan reviews to reflect the amelioration of risk factors or the identification of new ones (Gover \& Richards, 2018). Importantly, Colorado's DV treatment programs are non-time driven: The time it takes to address and reduce clients' risks and needs and achieve required competencies dictates a clients' time in treatment.

Regarding responsivity, Colorado's standards mandate that treatment be psychoeducational in nature, with Level $\mathrm{C}$ treatment also including crisis management and cognitive skills treatment (Gover \& Richards, 2018). And, consistent with the treatment principle, the standards outline required training elements and credentials for DV treatment staff and rely on a multi-disciplinary treatment team (MTT), including a treatment provider, probation officer, and victim advocate, to manage DV treatment clients; MTTs may include members from other state agencies dependent on the client's individual treatment plan (e.g., child protective services).

In service to the fidelity principle, treatment providers are required to meet minimum requirements to achieve certification to operate in Colorado and, as previously noted, the DVOMB is statutorily mandated to complete research regarding Colorado's standards. For example, in collaboration with the DVOMB, Gover, Richards, and Tomsich (2015) completed a process analysis to assess the level of implementation of the standards across the state's treatment providers. An online survey was conducted with MTT members including treatment providers $(n=55)$, state probation officers $(n=39)$, and victim advocates $(n=13)$. Findings demonstrated that the majority of MTT members endorsed implementation of the standards; however, differences were uncovered regarding the extent of implementation as well as the elements of the standards implemented (e.g., use of the DVRNA, levels of treatment, and offender competencies) across different MTT member types. These findings were used by the DVOMB to inform certification processes to encourage uniform implementation across the state and to develop messaging to providers regarding further implementation.

In 2018, Gover and Richards completed an additional, external evaluation of Colorado's treatment model, using treatment provider interviews and document reviews to assess providers' integration of the core competencies into their treatment 
curriculum and their strategies for evaluating clients' achievements of core competencies. Findings suggested variability regarding the alignment between the core competencies and treatment curriculum with some providers failing to address one or more core competencies all together; treatment curricula also often covered information that was outside of the scope of the core competencies. Results further indicated that treatment providers use divergent strategies to determine whether a client had achieved the core competencies (e.g., clinical judgement, assessments, treatment plan reviews, personal change plans); and that most providers relied on clinical judgement as opposed to standardized assessments.

Collectively, these findings suggest areas for improvement regarding the integration of PEIs into Colorado's approach to DV treatment. For example, adherence to the fidelity principle could be strengthened by the development of measures for providers to use in assessing their curriculum's alignment with the core competencies. Similarly, more clearly defined metrics to determine clients' achievement of competencies would be beneficial. Clinical judgement, as described by one provider as, "we'll know when you're done" is an approach that is subject to inconsistencies and biases (both intentional and unintentional) and introduces challenges for mapping out a treatment timeline for clients, both of which may negatively impact rapport building. Also, given that Colorado's DV treatment programs operate under a fee for service model, the non-time driven approach makes it difficult for providers to give clients an estimate of the expected cost of treatment. In addition, it is important to highlight the differential access to resources such as trained staff and agencies partners that provide ancillary services like mental health and substance abuse treatment across DV treatment programs in Colorado's rural versus urban areas. Furthermore, even in light of the DVOMB's statutory mandate to conduct research on DV treatment program practices in Colorado, there are no rigorous outcome studies examining the "Colorado model," and, at the same time, Colorado treatment providers report feeling "over-researched" (Gover \& Richards, 2018). Thus, Colorado would likely benefit from a strategic plan regarding research and evaluation of DV treatment program outcomes which is developed in consultation with treatment providers and clearly disseminated statewide.

\section{House of Ruth Maryland's Gateway Project}

Another example of the integration of the PEI framework into DV offender treatment stems from an ongoing initiative at House of Ruth Maryland's Gateway Project, in Baltimore City, Maryland - a state that has some of the least restrictive DV treatment (referred to as Abuse Intervention Treatment or AIPs) standards in the country. Maryland's state standards were first developed in the mid-1990s when the Maryland Family Violence Council's (MFVC) Post- Disposition Committee took up the issue of Abuse Intervention Program (AIP) standards (Murphy, 2002). After considerable debate, the committee decided to diverge from the majority of states, which had developed extensive program requirements - often codifying them in state statute - and instead adopted general operating guidelines for treatment programs which focused on promoting offender accountability and victim safety (Murphy, 
2002). The MFVC also established a treatment program certification process, and established the Maryland Abuse Intervention Collaborative (MAIC) with the goal of bringing researchers and program practitioners together to conduct and utilize empirical research to promote best practices for Maryland AIPs and to strengthen the AIP guidelines based on research findings (Murphy, 2002).

While favoring general operating guidelines over more rigid state standards forgoes the adoption of uniform program practices, it also allows programs the flexibility to develop practices to best serve unique client populations. For Baltimore City's House of Ruth Maryland, this is particularly important given that it serves clients with differing identities and life challenges than those clients served by providers in suburban and rural Maryland. The Gateway Project, House of Ruth Maryland's intervention for English-speaking abusive partners, serves a disproportionately African American population who live in economically distressed and disenfranchised neighborhoods and face high rates of violent crime. Likewise, Gateway Project clients report the highest rates of criminogenic risks and needs (e.g., criminal history, unemployment, substance use) when compared to clients across Maryland AIPs and, consistent with many other AIPs, significant rates of treatment attrition (Richards \& Murphy, 2018).

Consistent with the responsivity, and treatment principles, Gateway Project staff, in consultation with nationally respected technical assistance providers and members of the impacted community, have invested nearly two decades in creating a culturally-competent AIP curriculum that is sensitive to the ways in which power and control in relationships are manifested by individuals who themselves experience discrimination, oppression, and social and economic disenfranchisement (House of Ruth Maryland, 2019). Further, the curriculum was developed with intentionality regarding the limited literacy and writing skills of the client population by using a $5^{\text {th }}$ grade vocabulary level and a reliance on discussions over "written work."

A recent statewide analysis of Maryland DV AIPs found that clients who completed the Gateway Project had significantly lower recidivism for all criminal offenses and violent offenses than no-shows and dropouts after controlling for a large number of background variables, including prior criminal offending (Richards \& Murphy, 2018). At the same time, this evaluation also found that Gateway Project clients had the highest overall level of recidivism among the sampled Maryland AIPs, along with very high average levels of prior criminal offending before enrolling in AIP, and high criminogenic risks, such as substance abuse and unemployment, that were associated with reoffending (Richards \& Murphy, 2018).

These findings provided empirical support for ongoing efforts by the Gateway Project staff to develop a new service delivery model to address common co-occurring problems in their clients. These results also helped provide a conceptual framework for the Gateway Project's ongoing efforts to integrate the strategic assessment of criminogenic risks and needs (risk principle) and targeted supportive services (needs principle), into their delivery of culturally sensitive DV treatment services (i.e., a "supportive services model"; responsivity principle). Gateway Project staff also initiated a new researcher-practitioner partnership to assist in the implementation and evaluation of these changes (fidelity principle). At the time of this publication, this collaborative evaluation was in the early stages of implementation. 
The current evaluation of the Gateway Project's supportive services model uses a quasi- experimental design to compare program attendance and criminal recidivism for two cohorts of DV offenders: one that attended the Gateway Project prior to implementation of the supportive services model (i.e., a historical sample); and one that is attending post-implementation of the supportive services model. Data gathered from the supportive services cohort will be further analyzed to test the impact of targeted services on recidivism risk. In addition, in-depth qualitative interviews will be conducted with a subsample of offenders to examine factors that influence the uptake of supportive services, participant satisfaction with the supportive services model, and suggestions for future improvements and enhancement.

This evaluation requires additional effort on top of DV treatment service delivery by Gateway Project staff - staff had to develop a new, more time-intensive, client intake interview including the range of criminogenic risks and needs; staff must actively provide clients with referrals to supportive services and complete followups on service acquisition; and a mechanism to reassess clients risks, needs, and service utilization at the time of treatment completion or the scheduled time of completion had to be developed and now must be delivered on an on-going basis. Even before these numerous activities, researcher-practitioner meetings to identify the project goals, processes, and shared workloads were necessary. And, there was the arduous task of obtaining funding which required the significant time commitment of a competitive federal grant application.

The development of this researcher-practitioner partnership, its implementation, and its success hinges on a longstanding relationship between the Gateway Project staff and the interdisciplinary researcher partners - (Tara Richards, Chris Murphy, and Charvonne Holliday). Importantly, this partnership developed gradually over the course of several smaller projects and several years, with the incremental nature of this partnership allowing all partners to build trust and rapport over time. The research partners served as faculty at Baltimore City/County universities and hailed from divergent, yet complimentary disciplinary backgrounds - criminology, psychology, and public health.

Two of the researchers began collaborating with the Maryland Governor's Family Violence Council's AIP Certification and Audit Process Workgroup through a process analysis of Maryland AIPs (i.e., Richards \& Murphy, 2016). These researchers had spent many years building their reputations in the local practitioner community by presenting at conferences hosted by community groups and local government, assisting organizations in trainings and webinars, and serving in leadership roles on community boards, and one partner, Chris Murphy, previously served as the Clinical Supervisor at an area AIP. They were also intentional in reaching out to leaders in the practitioner community regarding their willingness to help when organizations needed research capacity. The process analysis examined 19 AIPs across the state and identified the Gateway Project as a "best practice" program among Maryland AIPs regarding its use of evidenced-based practices, adherence to the Maryland state standards, and resource allocation in support of AIP clients and program staff (Richards \& Murphy, 2016).

Then, in 2016, Richards and Murphy built on the process analysis by completing an evaluation of the relationship between the Maryland AIP completion and 
recidivism reduction (i.e., Richards \& Murphy, 2018). The Gateway Project served as the largest participating AIP in the sample from the process analysis (i.e., 19 AIPs from across the state), and these researchers worked collaboratively with Gateway Project staff to develop program-specific results and recommendations which were presented to funders and used in a Baltimore Sun Op-Ed penned by House of Ruth Maryland's Chief Development Officer. The third researcher, Charvonne Holliday, had recently completed an extensive concept-mapping study of Gateway Project clients, which centered on community-level risk and protective factors associated with IPV perpetration, and barriers and facilitators to help-seeking (Holliday et al., 2019). Her focus on IPV and health disparities from a public health perspective and her unique expertise on the structural and cultural barriers to help-seeking among the population served was critical to advancing a model that was responsive to the needs of Gateway Project clients.

Taken together, Richards and Murphy's process analysis and outcome evaluation, as well as Holliday's research on risk and protective factors in Maryland DV treatment programs, align with prior research calling for the integration of the PEI into DV treatment and reveal encouragement for their proliferation. These studies identified the Gateway Project as "fertile ground" for further infusion of PEI into DV offender treatment. And, importantly, the Gateway Project staff were interested and excited to empirically examine the impact of their years of hard work on client outcomes. The natural next step was to develop this researcher- practitioner partnership and evaluate the Gateway Project's supportive services model. At the same time, building the plane while you fly it is not easy, especially for the pilot! And here, the Gateway Project staff are the primary "builders" and "pilots" of the plane. As described above, they must continue to provide treatment to clients while also developing and implementing significant programmatic changes and assisting in daily tasks associated with data collection. In entering into this partnership, their jobs no doubt got more difficult and "bigger", without gaining any more hours in the day, and the perspective from the "front line" offers valuable insight and information for both scholars and practitioners who are considering collaborations.

\section{Programmatic Applications \& Integration}

In 2000, Gateway Project staff began to identify community partners who could provide informal support to program clients for needs beyond those addressed in their DV treatment curriculum. Partnerships were formed with professionals in the fields of employment, mental health, and parenting. In 2019, the program began institutionalizing what, up until then, had been an informal process. Additionally, Gateway Project elected to continue their existing partnership with a local organization who provides co-occurring treatment for DV offenders with a diagnosable substance use disorder. In collaboration with the research team, Gateway Project staff started the process of revising the intake assessment, so that it would directly align with the supportive services that would be offered and identify clients who needed services; a post- treatment assessment was also created. Through this process, the intake assessment increased from 14 pages to 26 pages, which in turn increased the time needed 
to complete an intake assessment from 30 to 45 minutes, to 60 to 90 minutes. This increased length created quite a bit of anxiety for staff - how would staff complete the intake and enter the information into the internal data system in the midst of their already busy day, and how would clients respond to a lengthy assessment? In order for staff to adequately complete the intake assessment while also meeting the needs of clients, there were multiple internal procedures that needed to be changed, including scheduling more time per assessment and breaks in between assessments, training staff on a variety of mental health-related topics, and developing quality assurance procedures for entering intake assessments into the internal database. The entire Gateway Project staff also completed Motivational Interviewing (MI) training and ongoing MI supervision to enhance the effectiveness of the initial interaction during the intake assessment.

Further, during initial implementation of the new intake assessment, Gateway Project staff identified several diagnostic instruments and specific items that were consistently problematic for clients - due to cultural literacy and/or a lack of comprehension. Collaborative, biweekly research team meetings with Gateway Project staff and the research team allowed time to discuss what was working and what needed to be adjusted. Replacement instruments and revised items were selected in order to develop an intake assessment that prioritized the program participants, while also meeting the needs of the evaluation design.

The new intake assessment was designed to build rapport between the Gateway Project staff and the client from the first interaction. Based on the needs identified in the intake assessment, the client is provided with information about the appropriate supportive service partners. Depending on the specific client's needs and interest level at intake, this can either be a warm handoff, in which the staff member will assist in connecting the client with the community partner, or a cold handoff where the staff member provides the client with the community partner's contact information. Then, approximately 4-6 weeks into the client DV treatment, a staff member follows up with each client regarding their interaction with the supportive service partners to whom they were referred. At this point, the staff member assesses whether the client is experiencing any barriers in accessing the supportive services. This process of accessing and addressing barriers to supportive services continues throughout the client's time in the program. Then, at the time of program completion, a post-treatment assessment is conducted for each client. The post-treatment assessment mirrors the intake assessment in regard to identifying client's service needs it. If the post-assessment identifies new or ongoing needs, supportive service partner information is again offered.

One challenge for Gateway Project staff has been working with the chosen employment partner. Most clients seeking employment want to be employed immediately, but the employment partner's process is better described as "preparation first, and then employment", which can feel slow to clients who have an expectation of immediate employment. Thus, the initial collaboration with the employment partner was not as successful as staff had anticipated. Gateway Project staff found that setting clear expectations with clients and maintaining transparent communication with community partners is imperative. The Gateway Project staff also elicited ongoing feedback from clients to ensure that their needs are being met. Gateway 
Project staff decided to continue to work with the current employment partner, but to also bring in additional employment partners, as well as identify employment partners with a variety of processes in order to meet clients' needs.

Due to the new structure of the program, the enrollment process has changed as well. The enrollment process now begins with an initial group orientation, and then an individual intake assessment - previously, the enrollment process included only an individual intake assessment. This change was made because the highest percentage of applicant drop-off happens from the point of making the initial appointment and actually coming in for that appointment. Moving the group orientation to be first meant that the number of expected participants that actually showed up for the session would have no impact on how many staff would be needed to facilitate the one session. The anticipated drop-off would take place, which meant staff members were scheduling fewer applicants for the individual intake session. Instead of having a 50\% no-show rate, they would have much higher attendance and therefore, could ultimately schedule fewer appointments, which allowed them to accommodate the longer interview time without overburdening staff. This new structure allows clients to receive information about the program as well as program rules and expectations in their first appointment with the program, instead of waiting until their first group treatment session. They also get an opportunity to have their questions answered and get a feel of what to expect in at group setting. Additionally, this change allows Gateway Project staff to meet potential clients and identify if they are appropriate for group.

Finally, the new program structure removed the fee clients were expected to pay at the time of their intake assessment. Gateway Project staff understood that asking an individual who may have lost a job as a result of being arrested or be unemployed to pay a fee for a program they have no interest in attending was a source of considerable contention on the part of new clients. Removing the intake fee aimed to decrease initial resistance by clients and in turn increase staff-client rapport and support overall client success. The program anticipates that these changes will increase retention and have a net zero impact on the overall revenue for the program.

\section{Conclusion}

While the integration of the PEI framework into DV offender treatment programming shows promise, big programmatic changes present philosophical and practical challenges. The PEI framework requires offender assessments be done to assess risk factors and criminogenic needs, and subsequently use the assessment findings to inform decisions about treatment intensity and content. Specifically, the treatment content must be responsive to an offender's risk factors and criminogenic needs. Supportive services should be made available and utilized to address offender needs that go beyond the scope of DV treatment. Notably, DV offenders' risk for recidivism should be continually and consistently evaluated over time to ensure treatment progression and completion.

Therefore, program staff must know, understand, and appreciate the PEI framework, as their buy-in will require extensive, ongoing training, and might require 
substantial changes from the status quo by the program staff. Staff concerns are legitimate and must be considered in developing a plan for the implementation and sustainability of a new philosophy and approach to treatment services. Initial intake assessments, as well as periodic client reassessments, will take more of the staff's valuable time. Community partnerships with supportive services must be developed and nurtured. Markedly, such partnerships may be especially difficult in rural areas where there are fewer providers who offer important supportive services. However, the expanded use of Telehealth, as its use has rapidly evolved during the COVID-19 pandemic, may provide a potential avenue to explore such challenges. Furthermore, smartphone apps and remote Alcoholic Anonymous and Narcotics Anonymous programs have also rapidly expanded to provide community and support to those with substance use disorders.

The integration of the PEI framework into DV offender treatment also provides a potential pathway to much needed funding. Historically, there have been no dedicated funding streams for DV treatment; at best, a DV treatment program may be part of a multiservice agency and benefit from state and/or federal money allocated to victim services by way of the agency's shared overhead costs. Recently, however, both Maryland and New York identified DV treatment programs among the correctional programs that are eligible to apply for Justice Reinvestment Act funding. This funding represents a separate pool of money specifically allocated for programs aimed at recidivism reduction; however, treatment programs must demonstrate that they are evidenced-based and provide data demonstrating that the program works to be eligible for funds.

In closing, the intent of this article was to provide an overview of the PEI framework and relevant studies as applied to DV offenders and their programming, to present preliminary study findings from programs currently transitioning to a PEI framework, to outline the successes and opportunities for improvement as learned from current programs embarking on the transition, and to provide practitioners' viewpoints on the transition process and the challenges they encountered. Initial study findings suggest that the PEI framework and its applicability to DV offenders and their treatment shows promise, providing cause for cautious optimism. We acknowledge that there are potentially significant challenges that program staff may encounter while transitioning programs to a PEI-informed approach; however, the potential advantages - including reduced recidivism and increased victim safety - offer an encouraging counterbalance worth further consideration and exploration.

\section{References}

Andrews, D. A. (2006). Enhancing adherence to risk-need-responsivity: Making quality a matter of policy. Criminology \& Public Policy, 5(3), 595-602.

Andrews, D. A., \& Bonta, J. (1995). The level of service inventory - Revised (LSI-R) manual. MultiHealth Systems.

Andrews, D. A., \& Bonta, J. (2001). LSI-R user's manual. Multi- Health Systems.

Andrews, D. A., Bonta, J., \& Hoge, R. D. (1990a). Classification for effective rehabilitation: Rediscovering psychology. Criminal Justice and Behavior, 17(1), 19-52. 
Andrews, D. A., Zinger, I., Hoge, R. D., Bonta, J., Gendreau, P., \& Cullen, F. T. (1990b). Does correctional treatment work? A clinically relevant and psychologically informed meta- analysis. Criminology, 28(3), 369-404.

Babcock, J. C., Armenti, N., Cannon, C., Lauve-Moon, K., Buttell, F. P., Ferreira, R., ... Solano, I. (2016). Domestic violence perpetrator programs: A proposal for evidence-based standards in the United States. Partner Abuse, 7(4), 355-460.

Babcock, J. C., Canady, B. E., Graham, K., \& Schart, L. (2007). The evolution of battering interventions: From the dark ages into the scientific age. In J. Hamel \& T. Nicholls (Eds.), Family Interventions in Domestic Violence: A Handbook of Gender-Inclusive Theory and Treatment (pp. 215-246). Springer.

Bonta, J., \& Andrews, D. A. (2017). The psychology of criminal conduct (6th ed.). Routledge.

Campbell, J. C., Webster, D. W., \& Glass, N. (2009). The danger assessment: Validation of a lethality risk assessment instrument for intimate partner femicide. Journal of Interpersonal Violence, 24(4), 653-674.

Cannon, C., Hamel, J., Buttell, F. P., \& Ferreira, R. (2016). A survey of domestic violence perpetrator programs in the United States and Canada: Findings and implications for policy and intervention. Partner Abuse, 7(3), 226-276.

Connors, A. D., Mills, J. F., \& Gray, A. L. (2012). An evaluation of intimate partner violence intervention with incarcerated offenders. Journal of Interpersonal Violence, 27(6), 1176-1196.

Connors, A. D., Mills, J. F., \& Gray, A. L. (2013). Intimate partner violence intervention for high-risk offenders. Psychological Services, 10(1), 12-23.

Dowden, C., \& Andrews, D. A. (2000). Effective correctional treatment and violent reoffending: A metaanalysis. Canadian Journal of Criminology, 42, 449-467.

Eckhardt, C. I., Murphy, C. M., Whitaker, D. J., Sprunger, J., Dykstra, R., \& Woodard, K. (2013). The effectiveness of intervention programs for perpetrators and victims of intimate partner violence. Partner Abuse, 4(2), 196-231.

EMERGE. (2000). EMERGE batterers intervention group program manual. EMERGE: Counseling \& Education to Stop Domestic Violence.

Farringer, A. J., Duriez, S. A., Manchak, S. M., \& Sullivan, C. C. (2019). Adherence to "What Works": Examining trends across 14 years of correctional program assessment. Corrections, 1-19.https:// doi.org/10.1080/23774657.2019.1659193.

Gendreau, P. (1996). The principles of effective intervention with offenders. In A. T. Harland (Ed.), Choosing correctional options that work: Defining the demand and evaluating the supply (pp. 117130). Sage.

Gendreau, P., \& Andrews, D. A. (1996). The Correctional Program Assessment Inventory (6th ed.). University of New Brunswick.

Gondolf, E. W. (2002). Batterer intervention systems: Issues, outcomes, and recommendations. Sage Publications.

Gover, A. R., \& Richards, T.N. (2018). An examination of domestic violence offender treatment content in Colorado and the relationship between treatment content and offender outcomes. Denver, CO: Colorado Division of Criminal Justice, Department of Public Safety. Approved by the Colorado Division of Criminal Justice, Department of Public Safety (CJAG- 2014-DJ-15-008683-06-01).

Gover, A. R., Richards, T.N., \& Tomsich, E. (2015). Colorado's innovative response to domestic violence offender treatment: Current achievements and recommendations for the future. Denver, CO: Buechner Institute for Governance, Criminology and Criminal Justice Research Initiative, University of Colorado Denver. Approved by the Colorado Domestic Violence Offender Management Board.

Hansen, J., Davis, C., Smith, J. M., \& Hilkey, S. (2016). Standards for treatment with court ordered domestic violence offenders: A process evaluation. Denver, CO. Colorado Department of Public Safety; Colorado Division of Criminal Justice.

Hilton, N. Z., \& Harris, G. T. (2009). Criminal justice responses to partner violence: History, evaluation, and lessons learned. In D. J. Whitaker \& J. R. Lutzker (Eds.), Preventing partner violence: Research and evidence-based intervention strategies (pp. 219-244). American Psychological Association.

Hilton, N. Z., Harris, G. T., Rice, M. E., Lang, C., Cormier, C. A., \& Lines, K. J. (2004). A brief actuarial assessment for the prediction of wife assault recidivism: The Ontario Domestic Assault Risk Assessment. Psychological Assessment, 16(3), 267-275.

Hilton, N. Z., Harris, G. T., \& Rice, M. E. (2010). Risk assessment for domestically violent men. American Psychological Association. 
Hilton, N. Z., \& Radatz, D. L. (2018). The criminogenic and noncriminogenic treatment needs of intimate partner violence offenders. International Journal of Offender Therapy and Comparative Criminology, 62(11), 3247-3259.

Hilton, N. Z., \& Radatz, D. L. (2021). Criminogenic needs and intimate partner violence: Association with recidivism and implications for treatment. Psychological Services. Advance online publication. https://doi.org/10.1037/ser0000450

Holliday, C. N., Morse, S. M., Irvin, N. A., Green-Manning, A., Nitsch, L. M., Burke, J. G., et al. (2019). Concept mapping: Engaging urban men to understand community influences on partner violence perpetration. Journal of Urban Health, 96(1), 97-111. https://doi.org/10.1007/s11524-018-0297-8.

Kropp, P. R., \& Hart, S. D. (1997). Assessing risk of violence in wife assaulters: The spousal assault risk assessment guide. Impulsivity: Theory, assessment, and treatment (pp. 302-325). The Guilford Press.

Kropp, P. R., Hart, S. D., Webster, C. D., \& Eaves, D. (1998). Spousal assault risk assessment: User's guide. Multi-Health Systems Inc.

Kropp, P. R., Hart, S. D., Webster, C. D., \& Eaves, D. (1999). Spousal assault risk assessment guide. Multi-Health Systems Inc.

MacKenzie, D. L. (2006). What works in corrections: Reducing the criminal activites of offenders and delinquents. Cambridge University Press.

Maiuro, R. D., \& Eberle, J. A. (2008). State standards for domestic violence perpetrator treatment: Current status, trends, and recommendations. Violence and Victims, 23(2), 133-155.

Radatz, D. L., \& Hilton, N. Z. (2019). Determining batterer intervention program treatment intensities: An illustration using the Ontario Domestic Assault Risk Assessment. Partner Abuse, 10(3), 269-282.

Radatz, D. L., \& Wright, E. M. (2016). Integrating the principles of effective intervention into batterer intervention programming: The case for moving toward more evidence-based programming. Trauma, Violence, \& Abuse, 17(1), 72-87.

Radatz, D. L., Hansen, J., \& Thomasson, C. (2020). Domestic violence treatment in Colorado: An overview of an evidence-based approach. Partner Abuse, 11(3), 268-291.

Richards, T. N., \& Murphy, C. (2016). A process analysis of Maryland Abuser Intervention Programs' (AIP) policies and guidelines. Baltimore, MD: Governor's Office of Crime Control and Prevention. Approved by Governor's Office of Crime Control and Prevention (BJAG-2014-0018).

Richards, T. N., \& Murphy, C. M. (2018). An examination of Maryland abuser intervention programs' $(A I P S)$ impact on domestic violence recidivism. Retrieved from Baltimore, MD.

Saunders, D. G. (2008). Group interventions for men who batter: A summary of program descriptions and research. Violence and Victims, 23(2), 156-172.

Scott, K., Heslop, L., Kelly, T., \& Wiggins, K. (2015). Intervening to prevent repeat offending among moderate- to high-risk domestic violence offenders: A second-responder program for men. International Journal of Offender Therapy and Comparative Criminology, 59(3), 273-294.

Smith, P., Gendreau, P., \& Swartz, K. (2009). Validating the principles of effective intervention: A systematic review of the contributions of meta-analysis in the field of corrections. Victims and Offenders, 4, 148-169.

Stewart, L. A., Flight, J., \& Slavin-Stewart, C. (2013). Applying effective corrections principles (RNR) to partner abuse interventions. Partner Abuse, 4(4), 494-534.

Stewart, L. A., Gabora, N., Kropp, P. R., \& Lee, Z. (2014). Effectiveness of risk-needs- responsivitybased family violence programs with male offenders. Journal of Family Violence, 29(2), 151-164.

Stewart, L. A., \& Power, J. (2014). Profile and programming needs of federal offenders with histories of intimate partner violence. Journal of Interpersonal Violence, 29(15), 2723-2747.

Van Voorhis, P., \& Salisbury, E. J. (2014). Correctional counseling and rehabilitation (8th ed.). Anderson Publishing.

Williams, K. R., \& Houghton, A. B. (2004). Assessing the risk of domestic violence reoffending: A validation study. Law and Human Behavior, 28(4), 437-455.

Publisher's Note Springer Nature remains neutral with regard to jurisdictional claims in published maps and institutional affiliations. 


\section{Authors and Affiliations}

Dana L. Radatz ${ }^{1} \cdot$ Tara N. Richards ${ }^{2}$. Christopher M. Murphy ${ }^{3} \cdot$ Lisa J. Nitsch ${ }^{4}$. Angelique Green-Manning ${ }^{4}$. Ann Marie Brokmeier ${ }^{4}$. Charvonne N. Holliday ${ }^{5}$

$\triangle$ Dana L. Radatz

dradatz@niagara.edu

Tara N. Richards

tararichards@unomaha.edu

Christopher M. Murphy

chmurphy@umbc.edu

Lisa J. Nitsch

lisanitsch@hruthmd.org

https://www.hruth.org

Angelique Green-Manning

amanning@hruthmd.org

https://www.hruth.org

Ann Marie Brokmeier

abrokmeier@hruthmd.org

https://www.hruth.org

Charvonne N. Holliday

cholliday@jhu.edu

1 Niagara University, Lewiston, NY, USA

2 University of Nebraska Omaha, Omaha, NE, USA

3 University of Maryland, Baltimore, MD, USA

4 House of Ruth Maryland, Baltimore, MD, USA

5 Johns Hopkins University, Baltimore, MD, USA 